\title{
内蒙古草原植被近地面反射波谱特征 与地上生物量相关关系的研究
}

\author{
王艳荣 \\ (内蒙古大学自然资源研究所, 呼和浩特 010021)
}

\begin{abstract}
摘 要 在 1994 2001 年 7 8 月期间, 对内蒙古草原的 15 个草地群落类型进行了反射波谱与生物学参数的测量, 在 1996、2001 年分别对其中的 7 个群落开展了反射波谱与生物学参数季节变化研究 利用 Duncan 方差分析、主分量 分析方法在 3 个空间尺度上讨论了不同群落类型波谱特征的差异性与可区分性。在大尺度上, 草甸草原、典型草 原和荒漠草原的植被反射波谱特征之间存在显著的差异，它们之间的平均鉴别错误概率小于 $20 \%$ ，在中小尺度上， 典型草原中不同群落之间波谱特征差异程度较高, 平均鉴别错误概率在 $15 \%$ 左右, 而在草甸草原和荒漠草原中, 不 同群落之间波谱特征的差异性较小。相关分析结果指出, 空间尺度和群落类型决定了地上生物量与植被指数之间 相关性的大小、相关形式以及植被指数的类型, 随着尺度的增大，生物量与植被指数的相关性趋于下降，在盖度较 高的草原群落中, 直线型的估产模型相关性最高, 估测精度大于 90\% , 而在覆盖度低于 30\% 40\%的荒漠草原群落 中，非线性估产模型相关性最高，估测精度只有 $85 \%$ 。对典型草原和荒漠草原估产模型的季节动态分析表明，在 6 月中旬至 9 月中旬期间的估产模型之间没有显著差异, 可以利用一个共同的估产模型来监测草地生物量季节动 态。
\end{abstract}

\section{关键词 近地面反射波谱 生物量 相关分析 尺度}

\section{CORRELATION ANALYSIS BETWEEN VEGETATION NEAR-GROUND REFLECTANCE SPECTRAL CHARACTERISTICS AND BIOMASS FOR INNER-MONGOLIA STEPPE}

\author{
WANG Yan-Rong \\ ( Natural Resources Institute, Inner Mongolia University , Huhhot 010021 , China)
}

\begin{abstract}
The spectral reflectance characteristics and biological parameters were measured for 15 grassland community types in Inner-Mongolia from 1994 to 2001. In addition, for seven community types , the seasonal variation of these parameters were measured in 1996 and 2001. At large spatial scales, the spectral reflectance was significantly different among meadow-steppe , typical-steppe and desert-steppe and could be distinguished by PCA with lower than $20 \%$ mean error. At medium to small scales, the ability to discriminate among community types in typical steppe was higher than at larger spatial scales (the mean error was about $15 \%$ ) but lower in both the meadow-steppe and desert-steppe. The results of correlation analysis indicated that the spectral reflectance characteristics of biomass and vegetation indices showed strongly significant correlations with spatial scales and community types. The strength of the correlation tended to decrease from small spatial scales to large scales. Linear models were best able to predict biomass from the spectral reflectance characteristics of communities that had high vegetation cover or biomass with an estimated reliability greater than $90 \%$. Non-linear models were the best predictors of communities with low vegetation cover $(<40 \%)$ and had an estimated reliability of about $85 \%$. From June to September, there were no remarkable differences among the estimated biomass models among different months which implied that we can utilize a common model to monitor the seasonal change of biomass for these grassland types.
\end{abstract}

Key words Reflectance spectral , Biomass , Correlation , Scales , Grassland community types , Inner Mongolia

20 多年来, 为了对草地生态系统进行有效地监 测和评价, 研究者们根据空间遥感资料或草地近地 面反射波谱数据建立了许多植被指数 (Vegetation in- $\operatorname{dex}$ ）,用来定量估测植被盖度、地上生物量、叶面积 指数等生态学参数及其时间动态 ( Jackson, 1983; Thomas \& Ching ,1987 ;Bartlett et al. ,1990;Rondeaux 
et al. ,1996) ,特别是归一化植被指数（Normalized difference vegetation index, NDVI) 不仅可以用来估测 生物量等参数, 还可以用来监测草地利用状态(如火 烧、过牧、干旱等) 及其变化 ( Pickup \& Chewings, 1994 ;Minor et al. 1999; Guo et al . 2000; Griffith et al. 2001)。

我国自 20 世纪 80 年代以来, 陆续开展了草地定 量遥感估产应用研究。徐希孺等 (1985) 指出比值植 被指数( Ratio vegetation index,$R V I$ ) 在草地定量遥感中 的潜在能力, 并对内蒙古草场生产力进行了评估; 王 艳荣等(1990,2001)对内蒙古锡林河流域的草地开展 了不同波谱参数与产草量的相关性研究; 黄敬峰等 (1999 2001)对天山北段天然草地牧草产量遥感动态 监测方法进行研究 建立了不同草地类型的线性与非 线性遥感监测模式，李京等(1993)、史培军等(1993)在 利用 NOAA/AVHRR 卫星资料对中国北方草地生物量 进行了遥感估测的研究中, 提出了分区估测的方法, 认为在利用遥感资料大范围估测草地地上生物量时， 在空间分辨率允许的条件下，应根据植被与环境特 征把研究区域划分若干估产子区，对每个子区分别建 立估产模型估测生物量, 有利于提高估产的精度, 体 现了尺度理论在遥感估产中的应用价值。由于内蒙 古草地面积较大, 群落类型复杂多样, 同时受研究尺 度、研究对象及取样方法不同的影响, 不同研究者建 立的草地光谱估产模型有较大差异(徐希孺等, 1985; 史培军等, 1993) , 其研究对象多为宏观区域尺度(对 应于植被分类中的植被型或植被亚型) 上的草地类 型，所建立的近地面或卫星遥感估产模型都为线性模 式, 而对中、小空间尺度(对应于植被分类中群系、群 丛组)上植被指数与产草量的关系很少关注, 此外, 由 于受研究时间所限, 多采用路线考察的方法进行波谱 特征与生物学参数测量, 数据量有限, 对估产模型的 精度检验不够。

作者在 1994 2001 年期间, 针对内蒙古草原具 有代表性的 15 个群落类型 (群丛组), 在生长旺季分 别进行了近地面反射波谱特征与生物学参数的测 量, 并对其中的 7 个群落类型开展了季节动态的研 究。本文拟在 3 个空间尺度 (大、中、小) 上评价不同 草地类型反射波谱特征的差异性, 分析不同群落类 型中植被指数与生物学参数的相关性及其季节动 态，所建立的不同尺度上的测产模式不仅可为不同 分辨率的卫星遥感测产研究提供理论依据, 而且小 尺度上的季节测产模式还可为草地生产与监测部门
提供新的常规测产途径，即利用草地反射波谱特征 从近地面迅速地、非破坏性地估测地上生物量 取代 传统的刏割测产方法。

\section{1 研究方法}

1.1 不同空间尺度上植被近地面反射波谱特征及 其与地上生物量的相关关系

在 $1994 \sim 1998$ 年 $7 \sim 8$ 月植物生长高峰期内, 以内蒙古锡林郭勒草原、乌兰察布草原中的地带性 植被-荒漠草原、典型草原、草甸草原的 5 个代表群 系( 贝加尔针茅 (Stipa baicalensis) 草原、羊草 (Leymus chinensis)草原、大针茅 (Stipa grandis) 草原、克氏针茅 ( S. krilovii) 草原和戈壁针茅 (S. gobica) 草原)中的 15 个主要群落为研究对象, 测量了它们的近地面波 谱特征及其生态学参数。植被近地面反射波谱的取 样和测定方法为: 使用两台 RS-II 型便携式 4 通道地 物波谱仪(其波谱范围分别与 TM 1 至 TM 4 波段相 同) , 在不同群落类型中各选择 3 4 个典型样区 (面 积约 $1 \mathrm{~km}^{2}$ )。在典型样区内, 沿双对角线及中心点, 各设 $5 \sim 6$ 个面积为 $1 \mathrm{~m}^{2}$ 样地, 测量植冠层、土壤背 景的组分光谱, 因仪器视场角小, 在每个样地中顺序 移动测量 10 次光谱, 取其平均值。波谱测定条件为 视场全光照，无风或微风，测定时间为上午 9:00 $11: 00$ 和下午 13:00 15:00 ,中午考虑到植物光合作 用存在 午休”现象，反射波谱特征会受到影响，一般 不进行波谱的测量。测量植被光谱后, 在同一样地 (面积为 $1 \mathrm{~m}^{2}$ ) 上, 测量种类组成、盖度、地上生物量 等生态学参数。

1.2 草原植被近地面反射波谱特征与地上生物量 相关关系的季节变化

由于群落优势植物及层片的季节发育节律各 异地上生物量随季节推移变化很大 植被的波谱特 征与地上生物量的相关性可能存在季节波动, 为了 达到对草地生产力适时动态监测的目的, 研究植被 地上生物量与植被指数相关性的季节变化是十分必 要的。在 1996、2001 年 5 9 月底期间, 以 1 个月为 时间间隔，对荒漠草原中的戈壁针茅群落、典型草原 中的羊草群落、大针茅群落及其在不同放牧强度影 响下形成的变体, 各设置了一个典型样区(面积约 1 $\mathrm{km}^{2}$ )。在典型样区内 沿双对角线及中心点, 各设 5 个样地(面积为 $1 \mathrm{~m}^{2}$ ), 在样区内的其它地段再各随 机设置 15 个样地, 分别开展了波谱特征及地上生物 量季节动态的定位测量, 具体测量方法与 1.1 同。 


\section{3 数据分析方法}

使用 Minitab 统计软件对各类数据进行分析。 主要分析方法有 Duncan 方差分析、主分量分析 (PCA) 和相关分析。使用了 3 种植被指数: RVI、 $N D V I$ 和垂直植被指数 ( PVI) , 将它们分别与地上生 物量进行 4 种类型的相关分析:直线、幂函数、指数 函数、对数函数。根据回归分析中相关系数和方差 的大小, 评价不同植被指数在估测草地地上生物量 中的优劣性 把相关系数和方差最大的相关方程认 为是该草地类型地上生物量估测的最佳模型。

比值植被指数 $R V I=R_{N} / R_{R}$

归一化植被指数 $N D V I=\left(R_{N}-R_{R}\right) /\left(R_{N}+R_{R}\right)$

垂直植被指数 $P V I=R_{N} \cos \varphi-R_{R} \sin \varphi$ 式中 : $R_{N} 、 R_{R}$ 分别是近红外、红光波段反射率, $\varphi$ 为 土壤回归线与 $X$ 轴的夹角。

\section{2 研究结果}

2.1 不同空间与时间尺度上草地植被近地面波谱 特征

在不同空间尺度上, 草地植物群落之间由于优 势植物不同生活型的差异、地上植物量 (或覆盖度)、 土壤背景特征的不同，在反射波谱特征上的差异程 度存在较大的变化。在区域 (植被亚型) 尺度上, 不 同地带性的草地植被 (草甸草原、典型草原、荒漠草 原)反射波谱特征之间差异极显著(图 1) ,利用可见 光波段反射率的组合可以在 $80 \%$ 的精度上予以鉴 别; 在中、小尺度上, 群落波谱反射特征的差异程度
与群落类型有关 :典型草原的 4 个代表性群落— 大针茅群落、克氏针茅群落、羊草群落、冷蓄 (Artemisia frigida) 群落在生活型组成或生物量上有 显著差异, 反射波谱特征的差异程度较高, 平均鉴别 错误概率小于 $15 \%$ （图 2)，但在荒漠草原中，只有在 灌丛化与非灌丛化群落之间波谱特征才有显著差 异, 而在非灌丛化群落类型中，不同群落之间反射波 谱特征差异较小, 难于区分, 草甸草原中主要群落的 反射波谱特征差异程度也较低。

在时间尺度上, 大针茅群落、羊草群落波谱反射 特征的季节变化趋势相似，可见光波段反射率的季 节变化与地上生物量的变化之间存在显著的相关 性，近红外波段反射率的季节变化幅度较小，与地上 生物量的变化无关。在 8 月初与 9 月初这两个时段 之间的群落反射波谱特征无显著差异，但是两者与 其它月份的反射波谱特征差异都较为显著。在戈壁 针茅群落中，红光和绿光波段反射率的季节变化趋 势均为逐月递减型, 蓝光和近红外波段反射率的季 节变化呈不规则的波动, 在 6 9 月期间, 植被反射 特征差异不显著(图 3)。

2.2 不同空间尺度上草地植被近地面波谱特征与 地上生物量的相关关系

利用 $1994 １ 998$ 年 7 8 月植被生长高峰期获 得的不同草地类型的近地面反射波谱特征和地上生 物量数据, 在 3 个空间尺度上进行波谱特征与地上 生物量之间的相关分析，建立了 3 个等级上的地面 光谱估产模型，其中 I 级模型用于区域 (大尺度)、II 级模型用于亚区域 (中尺度)、III级模型用于斑块

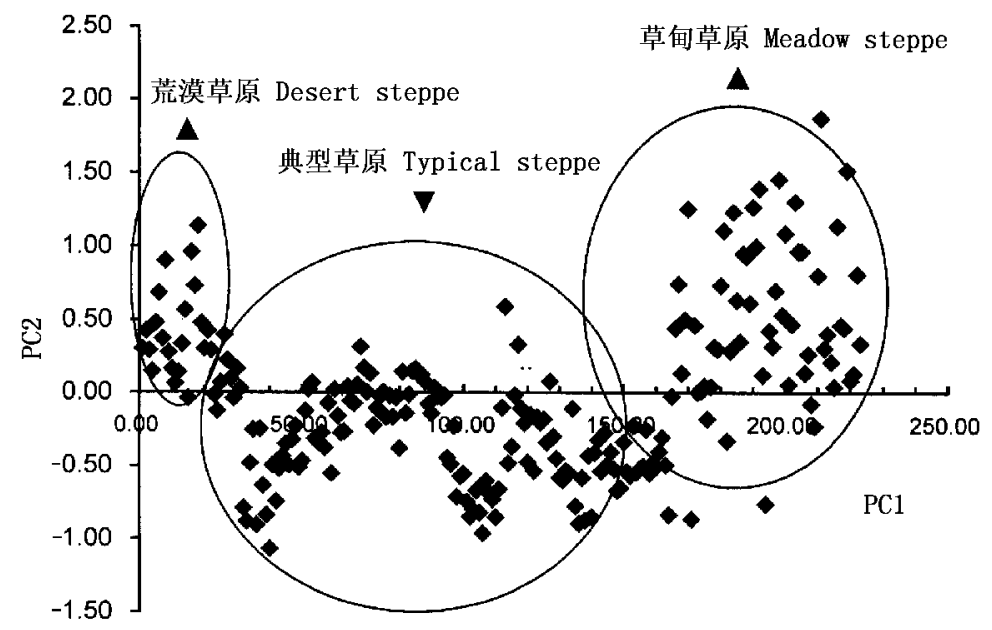

图 1 区域尺度上不同草地类型的 PCA 排序

Fig. 1 PCA ordination of different grassland types at regional scale 


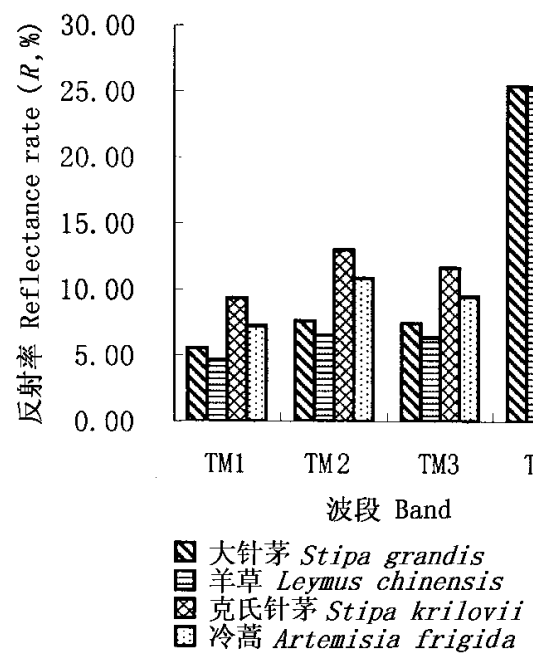

图 2 典型草原不同群落反射波谱特征

Fig.2 Reflectance spectral of different community types in typical-steppe

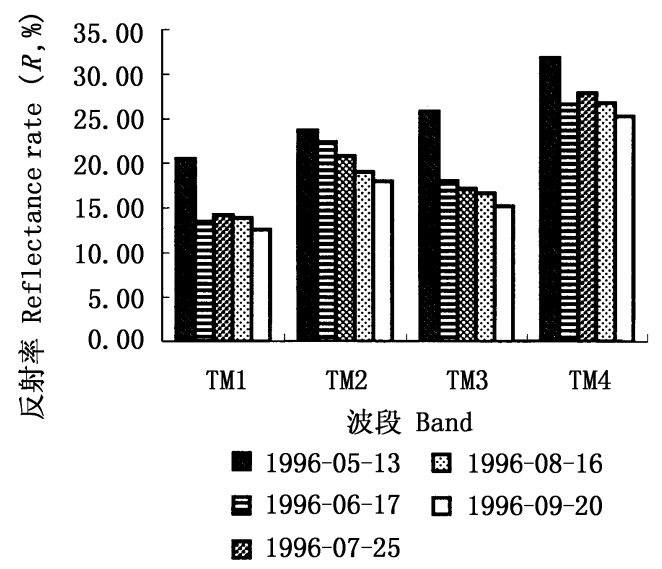

图 3 戈壁针茅草原反射波谱特征的季节动态

Fig.3 Seasonal change of reflectance spectral for Stipa gobica steppe

(小尺度)地上生物量估测 (表 1 表 2)。

对这些相关模型的进一步分析表明:1）虽然在 3 个空间尺度上,估产模型中地上生物量与植被指 数的相关性都达到了极显著水平，但从整体上分析， 生物量与植被指数的相关性大小与估产对象的空间 尺度呈反比，即相关性大小顺序为: : 级 $<$ II 级 $<$ III 级估产模型。2) 对于不同的草地类型，估产模型中 使用的最适植被指数各异,典型草原使用含红光和 近红外波段反射率的植被指数与地上生物量的相关 性最高 草甸草原红光波段反射率由于有饱和效应， 对较高水平上的地上生物量变化反应迟钝，其地上 生物量更适于利用含蓝光和近红外波段反射率的植 被指数估测 荒漠草原、典型草原中某些地上生物量 较低的群落, 估产模型也更适于使用含蓝光、绿光波 段反射率的植被指数。3) 在相关形式上,具有 $30 \%$ $\sim 40 \%$ 以上植被盖度的群落, 其估产模式均为简单 的直线关系，而盖度较低的群落类型(如荒漠草原的
各种群落、典型草原中的小禾草草原等)更适于使用 非直线形式的估产模型。4) RVI 和 NDVI 之间存在 极显著的相关关系，与地上生物量的相关性大小相 近, 而在大多数群落中, $P V I$ 与地上生物量之间的相 关性低于前两者。

2.3 草地植被近地面波谱特征与地上生物量相关 性的季节变化

2.3.1 羊草草原波谱特征与地上生物量相关性的 季节动态

对羊草草原 5 月底至 9 月底地上生物量与反射 波谱特征之间的相关分析 (表 3) 表明 :

1) 在不同的生长阶段,群落地上生物量与 $R V I 、 N D V I$ 之间都存在极显著的相关性, 相关性大 小顺序为: 6 月底 $>8$ 月底 $>7$ 月底 $>5$ 月底 $>9$ 月 底 即估产模式在 6 月底相关性最高, 在 9 月底最 低。2)在 6 8 月期间, 以直线型估产模式相关性 最高, 而在 9 月初至 9 月底之间, 相关性最高的是对 数形式的估产模式。3) 不同月份之间, 使用相同植 被指数和相同相关形式生成的估产模式也存在差 异, 表现为: 使用 $R V I$ 估产时, 5 月底和 9 月底的估 产模式之间不存在显著差异, 7 月初、 8 月初和 9 月 初的估产模式之间也不存在显著差异;而使用 NDVI 估产时 5 个月份的估产模型之间均无显著差异, 可 以合并成为一个估产模型 $: Y=786.00 N D V I-1.70$, $R=0.85^{\text {** }}, F=212.10, n=84$ 。4) 除 7 月初外， 土壤背景的红光、近红外波段反射率在其它 4 个月 份之间都存在极显著的相关关系, 方差分析表明这 4 个月份的土壤回归线之间无显著差异, 可以用下 式表示: $P_{S 4}=1.02 P_{S 3}+9.94, R=0.90, F=292.22$ ， $n=60$ 。利用各月的土壤回归线得到的 $P V I$ 与地上 生物量的相关性低于 $N D V I$ 和 $R V I$ 。

中 (轻) 度退化的羊草草原波谱特征与地上生物 量的相关关系与不退化的羊草草原相似, 但是受放 牧强度的影响, 群落内植物种类组成和地上生物量 分布较不均匀, 月际间的估产模型差异较大, 表现 为 5 月底和 9 月底的估产模型之间无显著差异, 但 二者与其它月份的估产模型彼此之间差异显著, 不 同月份之间的土壤回归线存在显著差异。

2.3 .2 大针茅草原波谱特征与地上生物量相关性 的季节动态

在 5 月底至 9 月底期间, 群落地上生物量与 $R V I 、 N D V I$ 之间都存在极显著的相关性,9 月底和 6 月底的估产模型相关性略高于其它时段,除 9 月底 外, 含绿光波段反射率的 NDVI 与地上生物量的相 
表 1 不同植被指数与地上生物量之间相关性

Table 1 Correlations between different vegetation indices and biomass

\begin{tabular}{|c|c|c|c|c|}
\hline \multirow{2}{*}{$\begin{array}{l}\text { 尺度 } \\
\text { Scales }\end{array}$} & \multirow{2}{*}{$\begin{array}{c}\text { 群落类型 } \\
\text { Steppe types }\end{array}$} & \multicolumn{3}{|c|}{ 相关系数 Correlation coefficient } \\
\hline & & $R V I$ & $N D V I$ & $P V I$ \\
\hline 区域 & 草甸草原 Meadow steppe & $0.514^{* *}$ & $0.515^{* *}$ & $0.540^{* *}$ \\
\hline \multirow[t]{2}{*}{ Region } & 典型草原 Typical steppe & $0.921^{* *}$ & $0.870^{* *}$ & $0.856^{* *}$ \\
\hline & 荒漠草原 Desert steppe & $0.772^{* *}$ & $0.737^{* *}$ & $0.637^{* *}$ \\
\hline 斑块 & 贝加尔针茅群落 Stipa baicalensis steppe & $0.651^{* *}$ & $0.610^{* *}$ & $0.578^{* *}$ \\
\hline \multirow[t]{5}{*}{ Patches } & 羊草群落 Leymus chinensis steppe & $0.892^{* *}$ & $0.908^{* *}$ & $0.799^{* *}$ \\
\hline & 大针茅群落 Stipa grandis steppe & $0.620^{* *}$ & $0.602^{* *}$ & $0.349^{* *}$ \\
\hline & 克氏针茅群落 Stipa krilovii steppe & $0.838^{* *}$ & $0.847^{* *}$ & $0.900^{* *}$ \\
\hline & 冷蕎群落 Artemisia frigida steppe & $0.688^{* *}$ & $0.644^{* *}$ & $0.744^{* *}$ \\
\hline & 戈壁针茅群落 Stipa gobica steppe & $0.651^{* *}$ & $0.610^{* *}$ & $0.578^{* *}$ \\
\hline
\end{tabular}

** : 在 $p<0.01$ 水平上显著相关 The correlations were significant at the $p<0.01$ level

表 2 不同空间尺度上草原地上生物量最适估测模型

Table 2 Optimal estimating models of biomass for the steppe types at different spatial scales

\begin{tabular}{|c|c|c|c|}
\hline $\begin{array}{c}\text { 群落类型 } \\
\text { Community types }\end{array}$ & $\begin{array}{c}\text { 估产模型 } \\
\text { Estimating models }\end{array}$ & $\begin{array}{c}\text { 相关系数 } \\
\text { Correlation coefficient }\end{array}$ & $\begin{array}{c}\text { 样方数 } \\
\text { Plot number }\end{array}$ \\
\hline \multicolumn{4}{|l|}{ 尺度 I :区域 Scale I :Region } \\
\hline 荒漠草原 Desert steppe & $Y=29.60 R^{2} I_{3}-26.8$ & $0.692^{* *}$ & 37 \\
\hline 典型草原 Typical steppe & $Y=164.0 R^{2} I_{3}-218.0$ & $0.840^{* *}$ & 29 \\
\hline 草甸草原 Meadow steppe & $Y=67.6 \mathrm{RVI}_{3}+82.0$ & $0.734^{* *}$ & 29 \\
\hline \multicolumn{4}{|l|}{ 尺度 II : 亚区域 Scale II Sub-region } \\
\hline 线叶菊草原 Filifolium sibiricum steppe & $Y=116.0 R V I_{1}+120.0$ & $0.768^{* *}$ & 20 \\
\hline 贝加尔针茅草原 Stipa baicalensis steppe & $Y=113.0 R V I_{1}-33.0$ & $0.702^{* *}$ & 20 \\
\hline 羊草草原 Leymus chinensis steppe & $Y=82.4 R V I_{1}+25.0$ & $0.737^{* *}$ & 20 \\
\hline 羊草、大针茅草原 Leymus chinensis + Stipa grandis steppe & $Y=61.9 \mathrm{RVI}_{3}+144.0$ & $0.444^{*}$ & 37 \\
\hline 大针茅草原 Stipa grandis steppe & $Y=105.0 \mathrm{RVI}_{3}-130.0$ & $0.510^{* *}$ & 39 \\
\hline 克氏针茅草原 Stipa krilovii steppe & $Y=101.0 R^{2} I_{3}-109.0$ & $0.689^{* *}$ & 45 \\
\hline 冷蒿草原 Artemisia frigida steppe & $Y=529.0 N D V I_{1}-65.0$ & $0.695^{* *}$ & 50 \\
\hline 戈壁针茅草原 Stipa gobica steppe & $Y=29.6 R V I_{3}-26.8$ & $0.692^{* *}$ & 37 \\
\hline \multicolumn{4}{|l|}{ 尺度 III 斑块 Scale III : Patch } \\
\hline 大针茅、羊草群落 Ass. Stipa grandis + Leymus chinensis & $Y=87.0 \mathrm{RVI}_{3}-12.3$ & $0.717^{* *}$ & 20 \\
\hline 大针茅、糙隐子草群落 Ass. Stipa grandis + Cleistogenes squarrosa & $Y=0.11 \mathrm{NDVI}_{3}+2.1$ & $0.698^{* *}$ & 18 \\
\hline 克氏针茅、䊁隐子草群落 Ass. Stipa krilovii + Cleistogenes squarrosa & $Y=48.3 R I_{3}-21.4$ & $0.551^{* *}$ & 18 \\
\hline 克氏针茅、羊草群落 Ass．Stipa krilovii + Leymus chinensis & $Y=86.1 R V I_{1}-91.3$ & $0.601^{* *}$ & 19 \\
\hline 冷蒿、克氏针茅群落 Ass. Artemisia frigida + Stipa krilovii & $Y=501.0 \mathrm{NDVI}_{3}-45.0$ & $0.687^{* *}$ & 20 \\
\hline 冷蒿、䊁隐子草群落 Ass. Artemisia frigida + Cleistogenes squarrosa & $Y=9.6 \mathrm{PVI}_{3}+209.0$ & $0.737^{* *}$ & 20 \\
\hline 戈壁针茅、无芒隐子草群落 Ass. Stipa gobica + Cleistogenes songarica & $\ln (Y)=1.87\left(N D V I_{1}\right)+1.5$ & $0.753^{* *}$ & 20 \\
\hline 戈壁针茅、多根葱群落 Ass. Stipa gobica + Allium polyrhizum & $Y=2458.0 \ln \left(N D V I_{1}\right)+928.0$ & $0.964^{* *}$ & 18 \\
\hline 冷蒿-无芒隐子草群落 Ass. Artemisia frigida + Cleistogenes songarica & $Y=61.3 R V I_{1}-28.1$ & $0.757^{* *}$ & 18 \\
\hline
\end{tabular}
中的 1 、3 分别表示蓝光、红光波段反射率 1.3 in vegetation indices showed the reflectance on blue, and red bands ,respectively

关性最高, 直线型估产模式在整个生长时期都为最 佳选择。方差分析表明:6 月底至 9 月底之间, 用 NDVI 形成的不同估产模式之间无显著差异, 可以用 一个模型描述, 但它们与 5 月底的估产模型差异显 著(表 3)。由于土壤表面枯落物的积累较多, 土壤 回归线的离散性很高, 因而 $P V I$ 与地上生物量的相 关性较低。

中 (轻) 度退化的大针茅草原波谱特征与生物量 的相关关系与不退化的群落相似, 5 月底和 6 月底 之间, 7 月底、 8 月底和 9 月底之间的估产模型差异
不显著。

2.3.3 戈壁针茅荒漠草原波谱特征与地上生物量 相关性的季节动态

该群落类型不同月份的地上生物量估测模式是 有差异的(表 3)。具体表现为：

1) 在 5 9 月期间, 群落地上生物量与 $R V I$ 、 NDVI 之间都存在极显著的相关性，不同月份的相关 性大小相似。2) 在 5 7 月份, 以幂函数估产模型 相关性最高, 在 8 月中旬相关性最高的是直线型的 估产模式, 而在 9 月中旬, 以指数形式的估产模式相 
关性最大。可见在地上生物量偏低的月份, 最适估 测模式为曲线形式, 而当地上生物量在较高水平变 化时 地上生物量与植被指数趋于直线相关。3) 在 6 月和 8 月中旬, 含红光、绿光和蓝光波段反射率的 植被指数与地上生物量相关性大小相似, 而在 6 月、 7 月和 9 月中旬, 含蓝光波段反射率的植被指数相 关性最大。4) 在不同月份, 使用相同植被指数和相 同相关形式的估产模式也存在差异，表现为:5 7 月之间的估产模式差异不显著，而它们与 8 月、 9 月 的估产模式之间存在显著差异。

\section{4 对草地估产模型精度的检验}

利用 1995 年 $7 \sim 8$ 月对不退化的大针茅草原、
中(轻) 度退化的粘隐子草、克氏针茅 (含大针茅) 草 原、不退化的羊草草原、重度退化的冷蕎草原和小针 茅-无芒隐子草草原的近地面反射波谱和地上生物 量数据，对 1996 年得到的 8 月初上述群落的地上生 物量估测模型进行了精度检验 (表 4) 结果指出, 典 型草原的 4 种群落不同年份地上生物量估测模型之 间的差异较小，地上生物量的估测精度在 $90 \%$ 以 上; 而荒漠草原由于植被盖度较低, 地上植物量极 低，土壤背景对反射波谱的贡献较大，不同年份的地 上生物量估测模型之间存在较大的差异, 生物量的 估测精度仅在 $85 \%$ 左右。

表 3 不同群落地上生物量估测的最适季节模型

Table 3 Optimal seasonal estimating models of biomass for different communities

\begin{tabular}{|c|c|c|c|c|}
\hline $\begin{array}{c}\text { 群落类型 } \\
\text { Community types }\end{array}$ & $\begin{array}{l}\text { 月份 } \\
\text { Month }\end{array}$ & $\begin{array}{c}\text { 估测方程 } \\
\text { Estimating functions }\end{array}$ & $\begin{array}{l}\text { 相关系数 } \\
\text { Correlation } \\
\text { coefficient }\end{array}$ & $\begin{array}{c}\text { 样方数 } \\
\text { Plot number }\end{array}$ \\
\hline \multicolumn{5}{|l|}{ 羊草草原 Leymus chinensis steppe } \\
\hline 不退化群落 & 5 月底 End of May & $Y=1307.0 \mathrm{NDVI}_{3}-190.0$ & $0.613^{* *}$ & 18 \\
\hline \multirow[t]{4}{*}{ No-degraded community } & 6 月底 End of June & $Y=1004.0 \mathrm{NDVI}_{3}-51.0$ & $0.726^{* *}$ & 15 \\
\hline & 7 月底 End of July & $Y=1359.0 \mathrm{NDVI}_{3}-355.0$ & $0.656^{* *}$ & 15 \\
\hline & 8 月底 End of August & $Y=1433.0 \mathrm{NDVI}_{3}-396.0$ & $0.587^{* *}$ & 17 \\
\hline & 9 月底 End of September & $Y=1414.0 \mathrm{NDVI}_{3}-222.0$ & $0.686^{* *}$ & 17 \\
\hline 中、轻度退化群落 & 5 月底 End of May & $Y=422.0 \mathrm{NDVI}_{3}-67.6$ & $0.620^{* *}$ & 17 \\
\hline \multirow[t]{4}{*}{ Middle ( or light) degraded community } & 6 月底 End of June & $Y=880.0 \mathrm{NDVI}_{3}-64.4$ & $0.630^{* *}$ & 15 \\
\hline & 7 月底 End of July & $Y=1158.0 \mathrm{NDVI}_{3}-471.0$ & $0.683^{* *}$ & 18 \\
\hline & 8 月底 End of August & $Y=1574.0 \mathrm{NDVI}_{3}-631.0$ & $0.686^{* *}$ & 14 \\
\hline & 9 月底 End of September & $Y=483.0 \mathrm{NDVI}_{3}-64.9$ & $0.634^{* *}$ & 18 \\
\hline \multicolumn{5}{|l|}{ 大针茅草原 Stipa grandis steppe } \\
\hline 不退化群落 & 5 月底 End of May & $Y=462.0 \mathrm{NDVI}_{3}-76.2$ & $0.563^{* *}$ & 17 \\
\hline \multirow[t]{4}{*}{ No-degraded community } & 6 月底 End of June & $Y=1373.0 \mathrm{NDVI}_{3}-372.0$ & $0.672^{* *}$ & 17 \\
\hline & 7 月底 End of July & $Y=1073.0 \mathrm{NDVI}_{3}-286.0$ & $0.632^{* *}$ & 16 \\
\hline & 8 月底 End of August & $Y=864.0 \mathrm{NDVI}_{3}-170.0$ & $0.614^{* *}$ & 19 \\
\hline & 9 月底 End of September & $Y=1332.0 \mathrm{NDVI}_{3}-331.0$ & $0.685^{* *}$ & 15 \\
\hline 中、轻度退化群落 & 5 月底 End of May & $Y=1003.0 \mathrm{NDVI}_{3}-71.2 .0$ & $0.717^{* *}$ & 15 \\
\hline \multirow[t]{4}{*}{ Middle( or light) degraded community } & 6 月底 End of June & $Y=909.0 \mathrm{NDVI}_{3}-258.0$ & $0.680^{* *}$ & 17 \\
\hline & 7 月底 End of July & $Y=858.0 \mathrm{NDVI}_{3}-282.0$ & $0.608^{* *}$ & 17 \\
\hline & 8 月底 End of August & $Y=551.0 \mathrm{NDVI}_{3}-120.0$ & $0.711^{* *}$ & 15 \\
\hline & 9 月底 End of September & $Y=426.0 \mathrm{NDVI}_{3}-65.8$ & $0.672^{* *}$ & 15 \\
\hline \multicolumn{5}{|l|}{ 冷蒿草原 Artemisia frigida steppe } \\
\hline & 6 月底 End of June & $Y=4711.0 \mathrm{NDVI}_{3}-24.8$ & $0.683^{* *}$ & 34 \\
\hline & 7 月底 End of July & $Y=613.0 \mathrm{NDVI}_{3}-96.3$ & $0.629^{* *}$ & 34 \\
\hline & 8 月底 End of August & $Y=716.0 \mathrm{NDVI}_{3}-171.0$ & $0.624^{* *}$ & 40 \\
\hline & 9 月底 End of September & $Y=955.0 \mathrm{NDVI}_{3}-329.7$ & $0.627^{* *}$ & 37 \\
\hline \multicolumn{5}{|l|}{ 小针茅草原 Stipa gobica steppe } \\
\hline & 6 月底 End of June & $\lg (Y)=1.93+0.92 \lg \left(N D V I_{1}\right)$ & $0.729^{* *}$ & 18 \\
\hline & 7 月底 End of July & $\lg (Y)=1.96+0.79 \lg \left(N D V I_{1}\right)$ & $0.572^{* *}$ & 20 \\
\hline & 8 月底 End of August & $Y=-40.0+48.5 R V I_{1}$ & $0.572^{* *}$ & 19 \\
\hline & 9 月底 End of September & $\lg (Y)=1.50+0.09 \lg \left(N D V I_{1}\right)$ & $0.640^{* *}$ & 19 \\
\hline
\end{tabular}

** : 在 $p<0.01$ 水平上相关显著 The correlations were significant at the $p<0.01$ level 植被指数中的 1.3 分别表示蓝光、红光波段反射率 13 in vegetation indices showed the reflectance on blue and red bands ,respectively 
表 4 对波谱估产模型的检验

Table 4 Test of the precision for the estimating models

\begin{tabular}{lccccc}
\hline \multicolumn{1}{c}{$\begin{array}{c}\text { 群落类型 } \\
\text { Steppe types }\end{array}$} & $\begin{array}{c}\text { 大针茅草原 } \\
\text { Stipa grandis }\end{array}$ & $\begin{array}{c}\text { 羊草草原 } \\
\text { Leymus chinensis }\end{array}$ & $\begin{array}{c}\text { 粘隐子草草原 } \\
\text { Cleistogenes squarrosa }\end{array}$ & $\begin{array}{c}\text { 冷蓠草原 } \\
\text { Artemisia frigida }\end{array}$ & $\begin{array}{c}\text { 小针茅草原 } \\
\text { Stipa gobica }\end{array}$ \\
\hline 误差均值 Error mean $(\%)$ & -4.87 & -8.71 & -3.43 & -5.49 & 17.52 \\
标准误差 Standard error mean $(\%)$ & 11.89 & 10.62 & 9.99 & 9.12 & 12.20 \\
样方数 Number of plots & 15 & 15 & 15 & 15 & 15 \\
\hline
\end{tabular}

\section{3 结论与讨论}

1)空间尺度和草地群落类型决定了地上生物量 与植被指数之间相关性的大小、相关形式以及植被 指数的类型, 随着研究尺度的增加, 地上生物量与植 被指数的相关性趋于下降。这个结果与李京等 (1993)、史培军等(1993) 的研究结论是一致的, 但是 他们对内蒙古草原只进行了大尺度 (植被亚型)上的 分区遥感测产研究, 基本上是为宏观遥感技术 (气象 卫星等)应用服务，本文的结论涉及了大、中、小 3 个 空间尺度,所建立的估产模型为使用更高分辨率的 卫星遥感数据估测产草量提供了理论依据。

2) 在现有的国内外相关研究中, 都是利用红光 与近红外波段反射率生成植被指数, 用来建立地上 生物量估测模型, 但本研究的结果指出, 在草甸草原 各种群落中, 以及在典型草原生物量较高的群落中 (例如羊草草原) 植被在红光波段的反射率具有” 饱 和”现象, 包含红光反射率的植被指数与地上生物量 的相关性趋于降低, 而包含蓝光波段反射率的植被 指数与地上生物量的相关性更高, 这一现象在以往 的相关研究中还未见报道过。

3) 在以往对内蒙古草地遥感测产研究中, 植被 指数与地上生物量的相关模型都是线性模型, 本研 究发现, 在草甸草原和大多数典型草原群落中, 确 实是直线型估产模型的相关性最高, 但在覆盖度低 于 30\% 40\%、地上生物量小于 $200 \mathrm{~g} \mathrm{FW} \mathrm{m}^{-2}$ 的绝 大多数荒漠草原群落和少数典型草原群落中, 植被 指数与地上生物量之间的最佳相关关系趋于非线性 型，上述结论与黄敬峰等 (2001) 在新疆干旱地区草 地建立的非线性测产模型是接近的。

4)在 3 类植被指数中, $R V I 、 N D V I$ 与地上生物量 之间都存在较高的相关性, 而且这两个植被指数之 间也总存在极显著的相关性, 但 $P V I$ 与地上生物量 的相关性在绝大多数群落中都低于 $R V I 、 N D V I$, 这种 现象的出现是由于草地土壤回归线的离散性造成 的,在典型草原和草甸草原中, 土壤回归线的离散 性主要是由于在土壤表面存在着数量不等、分布不
均的植物枯落物造成的, 而在荒漠草原中, 土壤表 面组成物质的差异 (如小砾石的粒度和数量) 可能是 造成土壤回归线离散的主要原因。

5)对典型草原和荒漠草原主要群落估产模型的 季节动态分析表明, 在 6 月中旬至 9 月中旬期间, 不 同群落中的估产模型之间差异不显著, 可以利用一 个共同的遥感估产模型来监测草地地上生物量季节 动态。

6)近地面波谱估产模型对典型草原各个群落地 上生物量的估测精度在 $90 \%$ 以上, 考虑到在传统的 刈割测产中由于剪割鲜草有一定的损失, 利用近地 面反射波谱特征迅速地、非破坏性地估测草地地上 生物量的方法, 无论从技术上还是估测精度上都是 可行的。但荒漠草原由于植被盖度、地上植物量较 低, 土壤背景对波谱的贡献较大 地上生物量的估测 精度仅在 $85 \%$ 左右, 近地面遥感估产方法无疑会带 来较大的误差。

\section{参 考 文 献}

Bartlett, D.S., G. J. Whiting \& J.M. Hartman. 1990. Use of vegetation indices to estimate intercepted solar radiation and net carbon dioxide exchange of a grass canopy. Remote Sensing of Environment, 30: $115 \sim 128$.

Griffith, J.A. , K.P. Price \& E. A. Martinko. 2001. A multivariate analysis of biophysical parameters of tallgrass prairie among land management practices and years. Environmental Monitoring and Assessment, 68: $249 \sim 271$.

Guo, X. L., K. P. Price \& J. M. Stiles. 2000. Biophysical and spectral characteristics of cool- and warm-season grasslands under three land management practices in Eastern Kansas. Natural Resources Research, 9:321 331.

Huang, J.F. (黄敬峰), X.Z. Wang (王秀珍) \& X.B. Hu (胡 新博). 1999. Studies on grass yield monitoring models for different natural grassland types using remote sensing data in northern Xinjiang. Grassland of China (中国草地), 1:7 18. (in Chinese with English abstract)

Huang, J.F. (黄敬峰), X. Z. Wang (王秀珍) \& X. B. Hu (胡新博). 2001. A study on monitoring and predicting models of grass yield in natural grassland using remote sensing data and meteorological data. Journal of Remote Sensing (遥感学报), 1: 69 74. (in Chinese with English abstract)

Jackson, R.D. 1983. Spectral indices in n-space. Remote Sensing of Environment, 13:409 421 . 
Li, J. (李京) \& Q. Yuan (袁清). 1993. Research on the methods of quantitative monitoring of grassland productivity by using the remote sensing date of NOAA/AVHRR. Journal of Natural Resources (自然资源学报), 4:365 373. (in Chinese with English abstract)

Minor, T., R. Lancaster, T. Wade, J. Wickham, W. Whitford \& K. Jones. 1999. Evaluating change in rangeland condition using multi-temporal AVHRR data and geographic information system analysis. Environmental Monitoring and Assessment, 59:211 223.

Pickup, G. \& V. H. Chewings. 1994. A grazing gradient approach to land degradation assessment in arid areas from remotely sensed data. Remote Sensing of Environment, 15:597 617.

Rondeaux, G., M. Steven \& F. Baret. 1996. Optimization of soiladjusted vegetation indices. Remote Sensing of Environment, 55: $95 \sim 107$.

Shi, P. J. (史培军), J. Chen (陈晋) \& Y. M. Zhang (张元 明). 1993. Research on the optical models of above ground biomass estimation and the different rules in space temporal of ground spectrums in the grassland of Inner Mongolia. In: Li, B. (李博) ed. The design on technical system of dynamic monitor- ing of grazing ecosystem and regional experimental practice. Beijing: China Agricultural Science \& Technology Press. $81 \sim 90$. (in Chinese)

Thomas, I. L., N.P. Ching, V. M. Benning \& J. A. D' Aguanne. 1987. A review of multi-channel indices of class separability. International Journal of Remote Sensing, 8:331 350.

Wang, Y.R. (王艳荣) \& S.P. Yong (雍世鹏) . 1990. A correlative analysis between spectral reflectance and yield of grassland on Xilingol, Inner Mongolia. Acta Phytoecologica et Geobotanica Sinica (植物生态学与地植物学学报), 13:258 266. (in Chinese with English abstract)

Wang, Y. R. (王艳荣) \& W. Y. Yong (雍伟义). 2001. The analysis and discrimination of spectral reflectance for grassland vegetation on different spatial scales. Acta Scientiarum Naturalium University Neimongol(内蒙古大学学报), 1: 83 88. (in Chinese with English abstract)

Xu, X.R. (徐希儒), L.F. Jin (金丽芳) \& C. G. Lin (赁常 恭). 1985. The principle and method for measurement of grass output of Inner-Mongolia grassland using NOAA-CCT. Acta Geographica Sinica (地理学报), 40:333 346. (in Chinese with English abstract) 